\title{
An overview on field and experimental evidences concerning seismic liquefaction induced settlement of buildings with shallow foundations
}

\section{Revisión de las evidencias de terreno y experimentales de asentamientos de edificios con fundaciones superficiales inducidos por licuación sísmica}

Fecha de entrega: 8 de septiembre 2011 Fecha de aceptación: 4 de noviembre 2011

\section{Daniele Bertalot}

Civil Engineering Department, University of Dundee, Nethergate, Dundee DD1 4HN, United Kingdom, d.bertalot@dundee.ac.uk

During earthquakes, loose saturated granular soils can experience a sharp rise in excess pore pressures and consequent strength loss as their structure attempts to compact, a phenomenon known as liquefaction. During and following liquefaction, soil pore fluid redistributes, causing the settlement of overlying structures. This paper describes and explains important field and experimental observations on the behaviour of buildings with shallow foundations on liquefied soil. Liquefaction failure is responsible for large economic losses, and is therefore a very current topic in geotechnical engineering research. This has been recently shown by the widespread building damages due to liquefaction of the foundation soil observed during earthquakes in Chile and New Zealand, such as the Maule earthquake in 2010, the Darfield earthquake in 2010 and the two earthquakes that hit the city of Christchurch in February and June 2011.

Keywords: earthquakes, liquefaction, settlement, field and experimental data, centrifuge testing

\section{Seismic liquefaction}

Earthquake induced liquefaction has been associated with several types of ground failures and structural damages observed during major earthquakes. While cases of sand liquefaction have been reported in technical literature since the $16^{\text {th }}$ century, the phenomenon was brought to the attention of the scientific community by the widespread failures that occurred during 1964 earthquakes in Japan
Durante los terremotos, suelos granulares saturados y sueltos pueden sufrir un aumento pronunciado del exceso de presiones de poro y consecuentemente una pérdida de resistencia cuando la estructura del suelo trata de compactarse. Este fenómeno es conocido como licuación. Durante y después de ocurrida la licuación, el fluido en los poros del suelo se redistribuye, causando el asentamiento de estructuras sobre yacientes. Este artículo describe y explica importantes observaciones de terreno y experimentales relacionadas con el comportamiento de edificios con fundaciones superficiales sobre suelo licuado. Falla por licuación es la causa de grandes pérdidas económicas y es por lo tanto un área de investigación de mucho interés actualmente en Ingeniería Geotécnica. Esto ha sido evidenciado recientemente por el extenso daño en edificaciones debido a licuación del suelo de fundación observado durante los terremotos de Chile y Nueva Zelanda, tales como el terremoto de Maule el 2010, el terremoto de Darfield el 2010 y los dos terremotos que golpearon la ciudad de Christchurch en febrero y junio del 2011.

Palabras clave: terremotos, licuación, asentamiento, datos de terreno y experimentales, ensayos de centrifugas

and Alaska (Seed and Lee, 1966). Through the last 50 years, earthquake induced liquefaction has proven to be a major source of economic losses, often resulting in both structural damages to buildings and infrastructures and ground failures. Soil liquefaction takes place, mainly as a consequence of earthquake loading (other causes may be strong machinery-induced vibrations and blast propagation), in saturated sandy deposits. The damaging 
nature of the phenomenon is increased by the fact that areas geologically susceptible to liquefaction, like river floodplains and shorelines, are often highly anthropized. Another category of soils strongly susceptible to liquefaction are man made earth-fills, which often host key facilities (e.g. port docks, artificial islands, earth dams). Seismic soil liquefaction can result in different typologies of ground failure, comprising of foundation bearing failure, lateral spreading, slope flow failures, sand boils and uplift of buried structures.

Shallow foundation bearing failure can occur as a consequence of the foundation soil's liquefaction, since the shear strength of liquefied soil degrades to values close to zero. In these conditions the foundation induced stresses can not be sustained and the soil fails resulting in building tilting and settlement (Figure 1a). In presence of liquefiable sloping deposits such shear strength loss may trigger flow failures. Lateral spreading has been observed in several situations involving mildly sloping ground, which often results in failure of retaining and superficial structures. A particular feature of lateral spreading is the appearance of cracks oriented perpendicularly to the direction of movement in the superficial crust of cohesive soil or pavement (Figure 1b).
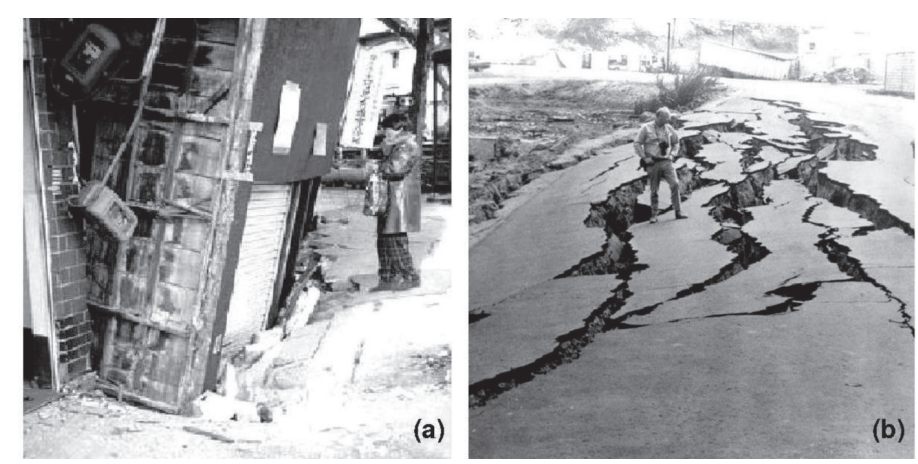

Figure 1: (a) Shallow foundation bearing failure, Kobe earthquake 1995 (EERI 1995) and (b) waterfront lateral spreading, Perú earthquake 1970 (USGS 2006)

Water erodes the soil on its way to the ground surface carrying with it some liquefied material, this results in a typical cone shaped deposit, known as a sandboil (Figure 2a). Another typical damage typology related to soil liquefaction is the buoyant weight increase of liquefied soils, this may result in the uplift of buried light structures such as tanks and utilities (Figure 2b).
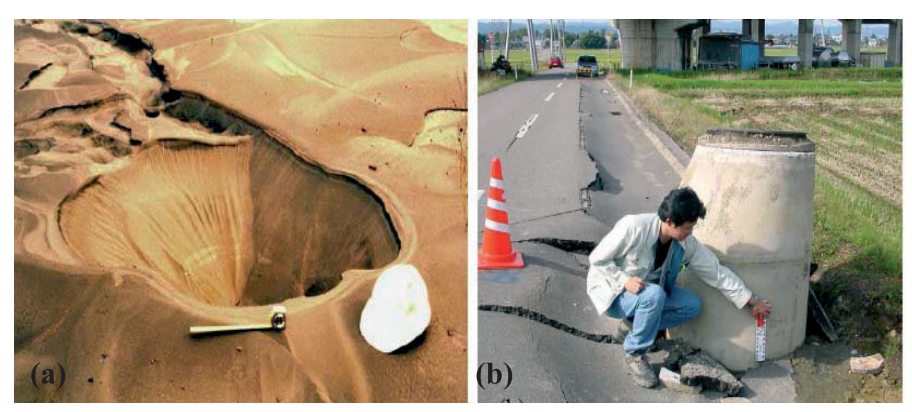

Figure 2:a) Sand boil, Loma Prieta earthquake 1979 (USGS 2006) and b) manhole uplift Niigata ken-Chuetsu earthquake 2004 (GEER 2004)

Post-liquefaction calculation methods have been proposed to assess the ground settlement without structures on it, i.e. on the free field (Tokimatsu and Seed, 1987; Ishihara and Yoshimine, 1992). However, the problem of liquefaction induced settlement of buildings with shallow foundations does not have a calculation procedure. Furthermore, the mechanics of this type of settlement is far from being well understood yet and its magnitude in case of an earthquake event is therefore difficult to estimate. Empirical charts based on the depth of liquefiable soil and building characteristics are currently available to estimate roughly the settlement of shallow foundations on liquefied soil. However, both field evidences and experimental results suggest that the confinement induced by the presence of a building on its foundation soil acts toward a reduction of the soils' liquefaction susceptibility, and should therefore be accounted for when estimating the induced settlement.

\section{Behaviour of shallow foundations on liquefied ground}

\section{Field data}

The sinking and tilting of buildings with shallow foundations on liquefied ground during earthquakes is a major source of damage, as the structures which suffer it often become unserviceable. Despite the undoubted relevance of this phenomenon complete data on the liquefaction induced settlement of shallow foundations are scarce. Most of the data usually collected in liquefaction sites consists of settlement and building tilt measurements only. However, to improve the understanding of the settlement mechanism, it is very important to know the composition and stratigraphy of the soil profile. Borehole logging, SPT and CPT tests in the proximity of the 
failed structure provide valuable information and allow an estimation of the liquefied soil thickness; however, because of the high cost of site investigation this is rarely the case. Moreover appropriate site investigations are often performed after the earthquake while in principle it would be ideal to have deeper site investigations prior to the occurrence of liquefaction of the ground.

Liquefaction damages were strongly brought to the attention of the scientific community following the 1964 Niigata earthquake, during which approximately 340 buildings were damaged as a consequence of foundation soil liquefaction. Yoshimi and Tokimatsu (1977) collected reliable data about the settlement of 35 reinforced concrete buildings in Niigata city, comprising of both building characteristics and soil conditions (Figure 3). In this study the thickness of the liquefied layer $\mathrm{D}_{\mathrm{L}}$ was estimated by the authors using the simplified procedure of Seed and Idriss (1971) for a peak ground acceleration of $0.16 \mathrm{~g}$ and relative densities estimated from the soil's standard penetration resistance SPT. The surveyed buildings ranged between 2 and 5 stories, some of them with basement; most of them had shallow foundations while the rest was founded on short piles whose length however did not influence in any case the whole liquefied layer. The presence of such piles and basements does not seem to affect the settlement behaviour of buildings.

A fairly well documented case of extensive liquefaction damages is represented by the Luzon earthquake of 1990 . During this earthquake liquefaction of the ground was observed in a wide area of Dagupan city, resulting in settlement and tilting of buildings. Adachi et al. (1992) analyzed the effect of buildings' geometric features on their settlement and tilting; the authors found the suffered settlement to be inversely proportional to either building width B (measured as the smallest plan dimension) or building area. Figure 3 shows that a clear trend can be individuated in the analyzed data when plotting the average settlement $\mathrm{S}$ against the width of the building B, both normalized by the depth of the liquefied sand $D_{L}$, as first noticed by Yoshimi and Tokimatsu (1977). Acacio et al. (2001) also analyzed the Dagupan case following the 1990 Luzon event, they observed that in presence of a thick enough unliquefied surface layer, very small or no building damages were observed; in particular no settlement was observed where this layer had a thickness over $3 \mathrm{~m}$. Moreover, Tokimatsu et al. (1994) observed that in the most affected area the surface layer is constituted, to depths between 5 and $10 \mathrm{~m}$, by sandy soils with SPT N-blows/foot lower than 30 . On the contrary, the unaffected areas present a surface layer of clay or dense sand. In the specific case of Dagupan City large settlements and tiltings were found to be a direct consequence of shallow foundation bearing failure due to soil liquefaction, and were concentrated on the banks of active or recently abandoned rivers and manmade fills.

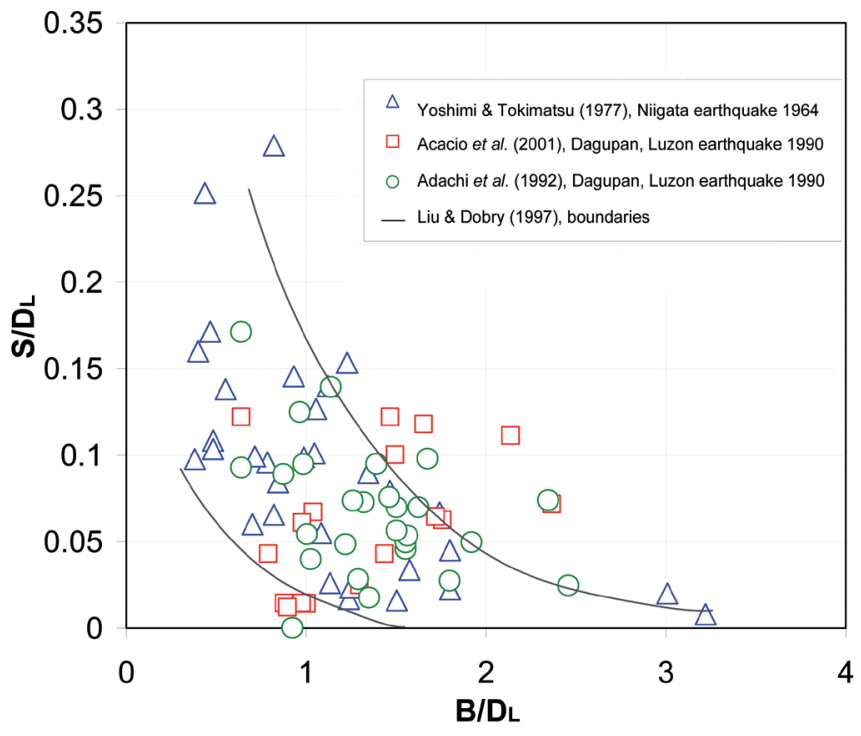

Figure 3: Normalized settlement $\mathrm{S}$ against normalized building width $\mathrm{B}$

Tokimatsu et al. (1994) also introduced a damage classification for the specific event, distinguishing in four categories of severity. It was observed that the damage severity to surface structures correlates fairly well with the estimated thickness of liquefied sand and with the shear wave velocity in the surface layer, damages being more severe where thicker liquefied layer characterized by lower values of shear wave velocity propagation were found. The tilting of buildings seems to be inversely proportional to building width and directly proportional to the amount of settlement. Field observations seem to stress the importance of the confining effect of adjacent structures in limiting building settlement. Buildings with similar characteristics founded on the same soil type were seen to settle less when surrounded by heavy structures than stand-alone buildings, corner buildings, spaced buildings or buildings surrounded 
by lighter structures. Foundation type also influences the damage severity to the superstructure. Buildings founded on individual footings were seen to suffer greater damages due to differential settlement, while buildings founded on raft foundations tended to sink or settle as a whole (Liu and Dobry, 1997). According to this hypothesis the confining effect of a building itself on the foundation soil should be taken in consideration when analyzing its settlement behaviour in case of liquefaction. Structures exerting higher contact pressure on the foundation soil should be expected to settle less, as the higher confinement reduces the susceptibility to soil liquefaction.

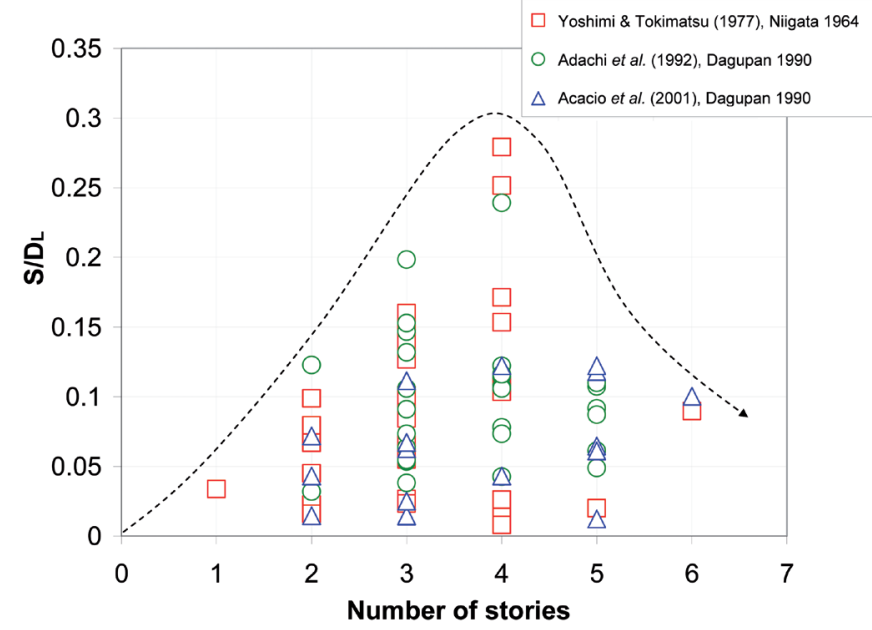

Figure 4: Effect of building number of stories on their induced settlement

As building contact pressure can not be easily estimated, in order to verify this hypothesis, Figure 4 shows the average building settlement $\mathrm{S}$ plotted against the building number of stories, which, provided the buildings are of the same typology, i.e. reinforced concrete structures, should be directly proportional to their foundation contact pressure.

\section{Experimental results}

Since the 1960's many authors have carried out experimental research on earthquake induced soil liquefaction. Thanks to these works the mechanics governing soil liquefaction is today fairly well understood. However, many related aspects like the settlement behaviour of superficial structures still requires further research. Two principal typologies of tests are generally used in liquefaction research: 1-g shaking table testing and dynamic centrifuge testing.

\section{Shaking table tests}

As the stress level in soils at any depth is mostly due to the self weight of the overlying portion of soil itself, the stress level reproduced in small scale tests is significantly lower than in situ one. Being soil liquefaction a highly stress dependent phenomenon, this stress dissimilarity introduces an indefinite degree of uncertainty in small scale shaking table tests' results. Despite this physical limitation such tests provided valuable information on the mechanism driving the liquefaction induced settlement of shallow foundations.

A common observation is that the soil right underneath the foundation models is less likely to liquefy after shaking of the model, with respect to the free-field. Yoshimi and Tokimatsu (1977) observed that the presence of a building with shallow foundation acts toward the reduction of the liquefaction susceptibility of the foundation soils in two ways. Firstly, the additional confining determined by the foundation contact pressure causes a reduction in the excess pore pressure ratios $r_{u}$, as the excess pore pressure required to cause initial liquefaction increases. Secondly, the additional shear stresses due to the foundation may trigger dilation in the soil, with the consequent generation of negative excess pore water pressures, hence further reducing the excess pore pressure ratios measured under the footing. The reduction in suffered settlement for wider buildings was also verified by the authors' results, obtaining values consistent with the field measurement in the Niigata and Luzon earthquakes (see Figure 5).

It is interesting to notice how the inclusion of walls embedded in the soil at the edges of the foundation model caused a marked reduction in settlement. This could be explained by the fact that the walls prevented, either lateral deformation of the sand toward the outside, and post-shaking redistribution of pore water pressures due to seepage from the free-field. Figure $6 a$ shows the experimental model used by Ghalandarzadeh and Khaki Khatibi (2003). They performed a series of shaking table tests all subjected to a sinusoidal input shaking of $3 \mathrm{~Hz}$ frequency and $0.28 \mathrm{~g}$ peak base horizontal acceleration. Their results confirm the effect of induced foundation confining observed by Yoshimi and Tokimatsu. In none of the tests $r_{u}$ reached $100 \%$ underneath the foundation, 
although higher values of $r_{u}$ were recorded by deeper Pore Pressure Transducers PPTs, as the foundation overburden effect reduces with depth. Failure patterns observed through a Perspex window clearly shows that the overall liquefaction induced settlement is a sum of three different mechanisms: lateral deformation due to softening of the foundation soil; shear strength loss determining a punching failure of the foundation; and settlement due to post liquefaction sand re-consolidation.

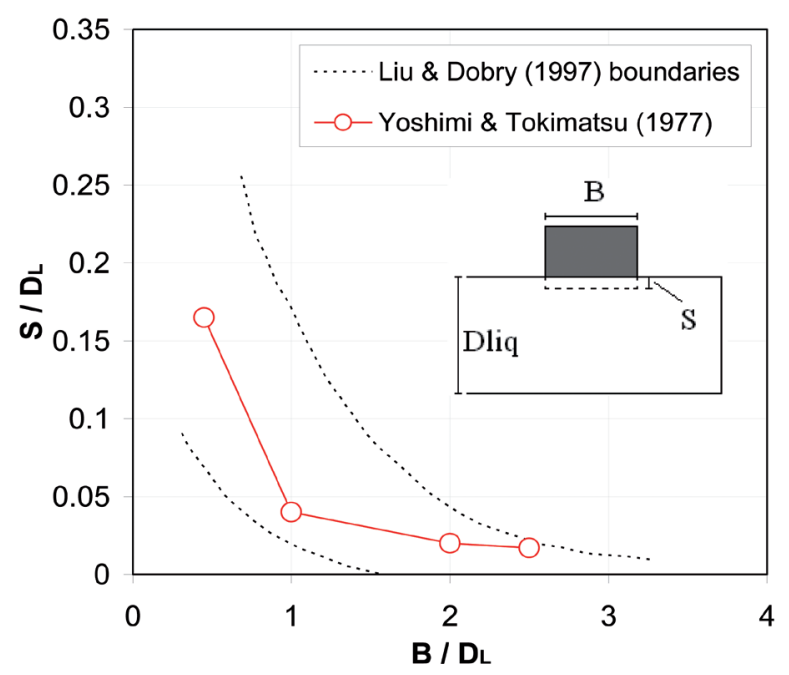

Figure 5: Effect of building width ratio on normalized settlement (Yoshimi and Tokimatsu, 1977) a)

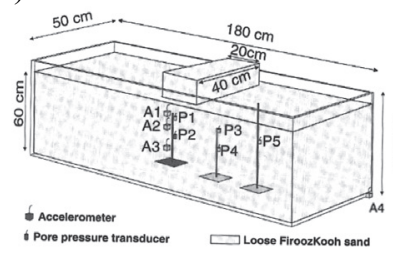

b)

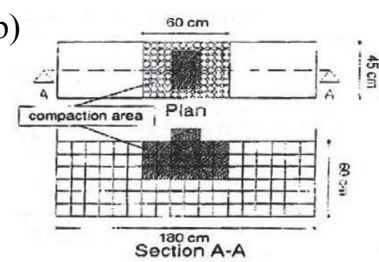

c)

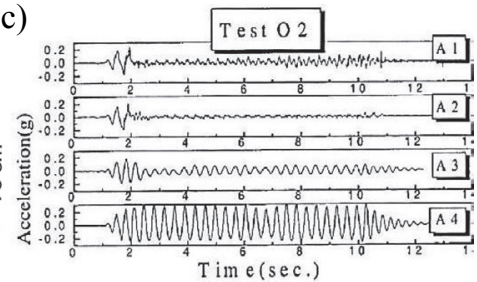

d)

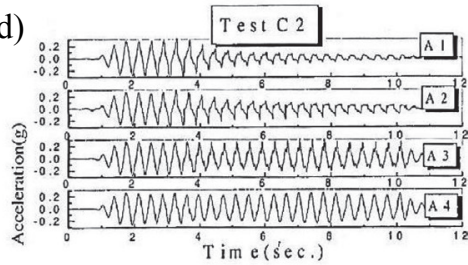

Figure 6: Influence of soil compaction on horizontal acceleration transmission, a) and b) model testing, c) and d) accelerations recorded (Ghalandarzadeh and Khaki Khatibi, 2003)

In one of the tests the effect of an area of compacted soil underneath the foundation was analyzed (Figure 6b). While the excess pore pressure traces showed lower peak values in the compacted soil during shaking, similar values of $r_{u}$ were reached after the end of shaking, probably due to seepage flow from the surrounding liquefied loose sand, in which a higher excess pore pressure generation occurred. However, from the analysis of acceleration traces shown in Figure 6d, it can be seen that, despite being beneficial by reducing excess pore pressure generation, the presence of compacted soil beneath the footing causes significantly higher horizontal accelerations to be transmitted to the soil surface and hence to eventual overlying structures.

\section{Centrifuge tests}

Soil's behaviour is dominated by gravitational effects, being its mechanical properties dependent on the stress level acting on the soil itself. Since physical modelling in geotechnical engineering generally involves testing of small scale models reproducing the interaction between soil and structures, testing such models at stress levels representative of the field conditions is very important in order to enhance the reliability of the results. For a model scaled with a factor of $1 / \mathrm{N}$ subjected to the earth's gravitational field, the effective stress will be $\mathrm{N}$ times lower respect to the prototype. Centrifuge modelling overcomes this problem by increasing the self weight of the soil itself by means of centrifugal forces; in particular if the model is accelerated to a value of $\mathrm{N}$ time earth's gravity $\mathrm{g}$, the stress distribution in the model will be equivalent to that in the prototype as demonstrated in the following,

$$
\begin{aligned}
& \sigma_{\text {prototype }}=\rho_{\text {soil }} \mathrm{gz}_{\text {prototype }} \\
& \mathrm{z}_{\text {model }}=\frac{\mathrm{z}_{\text {prototype }}}{\mathrm{N}} \\
& \sigma_{\text {model }}=\rho_{\text {soil }} \mathrm{gNz} \text { model } \\
& =\rho_{\text {soil }} \mathrm{gN}\left(\frac{\mathrm{z}_{\text {prototype }}}{\mathrm{N}}\right)=\sigma_{\text {prototype }}
\end{aligned}
$$

One of the first series of dynamic centrifuge test investigating the behaviour of shallow foundations resting on liquefiable ground was performed by Whitman and Lambe (1982) on the Cambridge University geotechnical centrifuge. Their model was tested at a centrifugal acceleration of $80 \mathrm{~g}$ and consisted of a circular brass foundation resting on a medium density uniform sand layer. The corresponding prototype under these conditions is a $9 \mathrm{~m}$ radius footing exerting a contact pressure of $130 \mathrm{kPa}$. The obtained results are in general accordance with $1 \mathrm{~g}$ shaking table tests, especially for what concerns excess pore water 
pressure generation, which was seen to be limited by the presence of the footing respect to the free-field. It is interesting to notice that the settlement was seen to cease with the end of shaking, while excess pore pressure beneath the foundation kept rising, reducing the effective stress to values in theory low enough to determine ultimate bearing capacity of the foundation soil. This behaviour may be due to the inertia forces generated in the foundation by the shaking, stressing the importance of 'Soil-Structure Interaction' in Soil Dynamics. However, as observed by Liu and Dobry (1997), if the soil and pore fluid, i.e. water, used in the model are the same in the prototype and the model is scaled to meet the dynamic requirement time $_{\text {prototype }}=$ Ntime $_{\text {model }}$, the soil in the model will behave as a material $\mathrm{N}$ times more permeable than the same soil in prototype conditions. Using water as model pore fluid therefore changes the excess pore pressure generation and dissipation regime. Figure 7 shows the effect of soil model permeability in a series of three centrifuge tests performed with different pore fluid of increasing viscosity (Liu and Dobry, 1997).
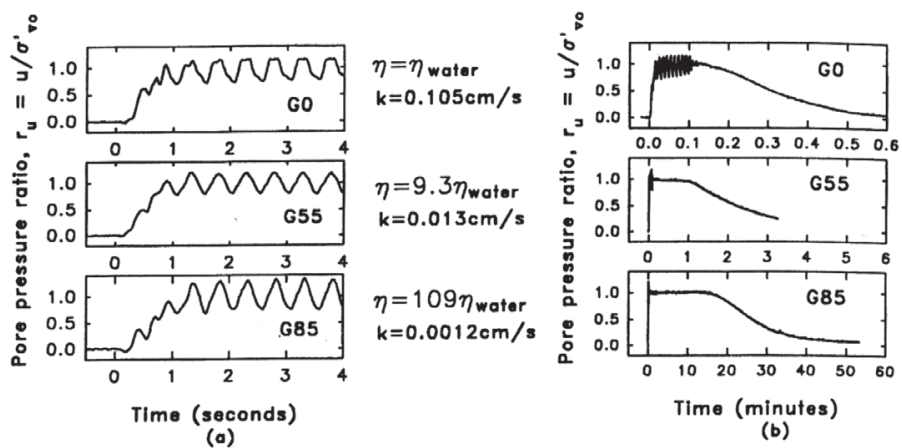

Figure 7: Influence of fluid viscosity (soil model permeability) on excess pore pressure generation and dissipation, a) $r_{u}$ in the first $4 \mathrm{~s}$ and b) $r_{u}$ versus time in minutes (Liu and Dobry, 1997)

In particular it can be easily noticed how for decreasing effective model soil permeability (higher fluid viscosity), the recorded peaks in both positive and negative excess pore pressure were seen to be higher and post shaking dissipation sensibly slower. By delaying excess pore water pressure dissipation beneath the foundation, the use of increased viscosity pore fluid causes a redistribution of the foundation's settlement pattern, with a higher percentage of it occurring after the end of the shaking. Therefore, in order to enhance the reliability of a model test's results, it appears very important to carefully match the model soil permeability with the one in the prototype.

A previous series of dynamic centrifuge tests performed by Liu and Dobry (1992) consisted in a circular footing (with a contact pressure of $125 \mathrm{kPa}$ ) resting on a layer of silty clay overlying a medium density uniform sand deposit. PPTs readings showed that the shaking was strong enough to cause full liquefaction in the free-field while the peak excess pore pressure ratio recorded under the foundation was 0.43 , and was measured sometime after the shaking has ended (Figure 8). The authors pointed out that maximum excess pore pressure ratios in the free-field were maintained far longer than the time necessary for the liquefied sand layer to undergo complete sedimentation, suggesting that stable water film formed in the free-field at the interface with the clay layer. Figure $8 \mathrm{c}$ shows a probable pattern of such water interlayer on the basis of the test's results; assuming a failure of the capping clay layer in the free-field, where the hydraulic gradient across it is higher, sand boils around the building would be generated, which is in accordance with many field observations.

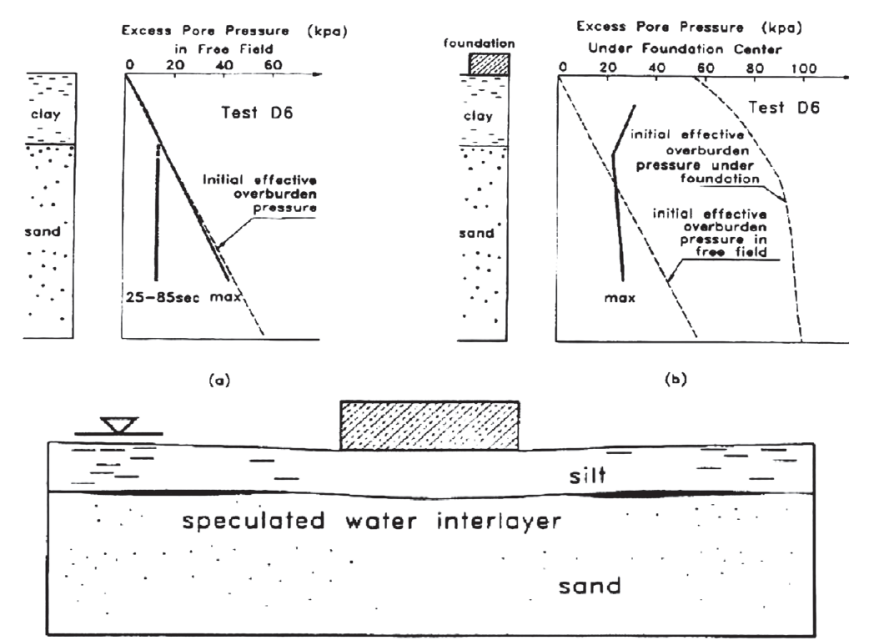

(c)

Figure 8: Excess pore pressure generation in layered soil model, (a) free-field, (b) under footing and (c) probable pattern of water interlayer generation (Liu and Dobry, 1992)

In order to reproduce a more realistic Soil-Structure Interaction SSI, Dashti et al. (2010) used in their centrifuge tests structural models compofsing of single-degree-offreedom structures, consisting in a lumped mass supported by steel columns mounted on a rigid aluminium rectangular footing. Figure 9 shows that the structural models represent two and four stories buildings with different foundation areas and contact pressures. 


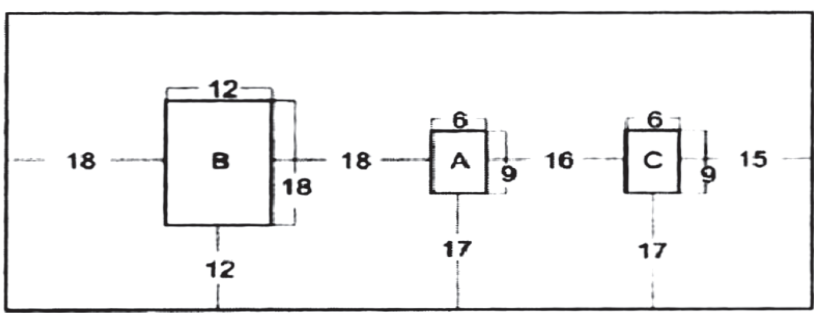

STMAKING DIRECTION

(a)

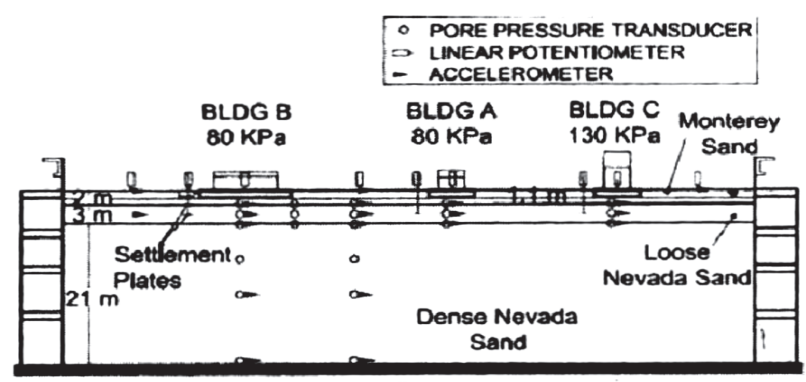

(b)

Figure 9: (a) Model top view and (b) cross-section (Dashti et al., 2010)

The behaviour of such structures was tested with various soil profiles; of particular interest was the comparison of their response on thin liquefiable sand layers with relative densities $\mathrm{D}_{\mathrm{R}}$ of $30 \%$ and $50 \%$. The medium density model with $D_{R}=50 \%$ was capped by a thin layer of non-plastic silt, in order to minimize capillary rise and liquefaction directly beneath the foundation. The presence of such layer acts toward a redistribution of the post-shaking settlement over a longer period of time, while it does not seem to have any influence during shaking. Comparing freefield and structural settlement shows how the difference between the two increases in presence of the silt capping layer. However, this difference reduces when more intense shaking is applied to the model, suggesting that it may be due to the higher sand relative density in the capped model delaying generation of high excess pore pressure. Denser sand requires more energy to generate excess pore pressure high enough to induce initial liquefaction with respect to a loose one, therefore for moderate intensity shaking might not have liquefied completely hence reducing the settlement in the free-field.

Lateral deformations in mildly sloping ground were seen to be distributed throughout the whole depth of uniform sand deposits, while, in presence of a low permeability capping layer, such deformations were concentrated right below it as a consequence of void redistribution (Fiegel and Kutter, 1994). A similar pattern has been observed in Dashti et al. (2010), however in this case the forces driving lateral deformation were the foundation induced shear stress rather than the static initial shear stress due to sloping ground.

Figure 10 shows an excavated section of the foundation soil after liquefaction, the deformed shape of the coloured sand columns clearly show a concentration of lateral strain at the sand-silt interface in the capped layer. This behaviour can be explained considering void redistribution in the upper portion of the sand layer, while in the uniform loose sand model the soil loosens more evenly.

(a)

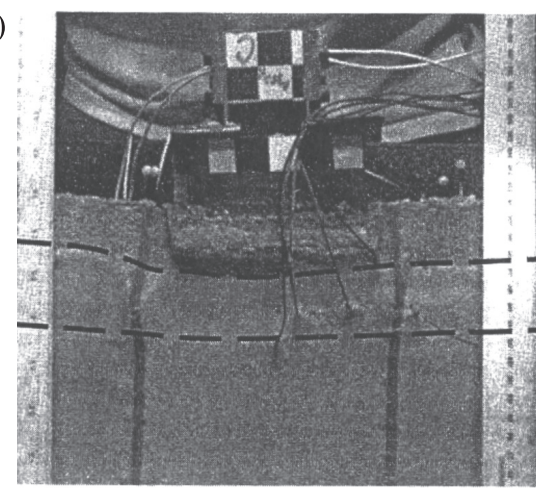

(b)

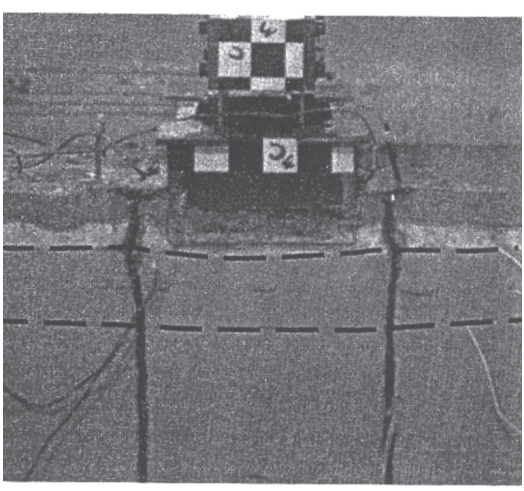

Figure 10: a) Lateral deformation pattern of loose, uniform sand model and b) medium dense, silt capped sand model (Dashti et al., 2010)

Despite saturated sands are erroneously thought to behave always in a fully undrained way during earthquakes, previous studies showed that local pore fluid migration may occur during shaking if a hydraulic gradient is present. Volumetric strains due to pore fluid redistribution $\varepsilon_{\mathrm{p}-\mathrm{DR}}$ should therefore be accounted for; their contribution to the overall settlement is thought to depend on many factors, 
including the magnitude of 3D hydraulic gradients and the soil layering. Dashti et al. (2010) classify the mechanisms contributing to liquefaction induced building settlement in two main categories: volumetric and deviatoric. The volumetric type, besides the deformations due to localized drainage $\varepsilon_{\mathrm{p}-\mathrm{DR}}$, comprises of: deformations due to postliquefaction sedimentation $\varepsilon_{\mathrm{p}-\mathrm{SED}}$, deformations due to consolidation during excess pore pressure dissipation $\varepsilon_{\mathrm{p} \text {-CON }}$ and volumetric expansion due to decrease in effective stress $\varepsilon_{\text {p-EXP. }}$ Volumetric mechanisms take place throughout the whole liquefiable deposit, while under and adjacent to the foundation model, additional mechanisms have been observed. These mechanisms belong to the deviatoric type, and consist in partial bearing capacity failure due to the loosening of the soil following excess pore pressure generation $\varepsilon_{\mathrm{q}-\mathrm{BC}}$ and soil-structure interaction due to horizontal accelerations transmission to the foundation, such as building ratcheting $\varepsilon_{\mathrm{q}-\mathrm{SSI}}$. Denser sands are less susceptible to volumetric deformation, however the overlying structures experience an amplified acceleration response increasing the severity of the deviatoric deformation component.

The results from dynamic centrifuge tests from different authors seem to confirm the effect of building width on the liquefaction induced settlement. In all cases wider buildings were seen to settle less, for all other parameters being the same, in accordance with Yoshimi and Tokimatsu (1977) observations. Figure 11 shows how most of the experimental settlement ratios measured by several authors fall inside, or very close, to the boundaries of the field data from the Niigata and Luzon earthquakes plotted by Liu and Dobry (1997). Settlement ratios measured in Hausler (2002) and Lambe and Whitman (1982) fall slightly out of the field data boundaries, however in the first case this may be explained by the very thick liquefied deposit (i.e. $20 \mathrm{~m}$ ) while in the second by the lower peak ground acceleration imparted to the model. Therefore it is assumable that for values of these parameters in line with the rest of the tests the measured settlement ratio would be higher, falling in the case history range. However, two out of three tests from Dashti et al. (2010) are clearly not consistent with the rest of the data, these two tests consisted of a thin liquefiable sand deposit (i.e. $\mathrm{D}_{\mathrm{L}}=3 \mathrm{~m}$ ), while the rest of the tests and field observations involved thicker liquefiable deposits ranging between 6 and $20 \mathrm{~m}$ (see Figure 11).

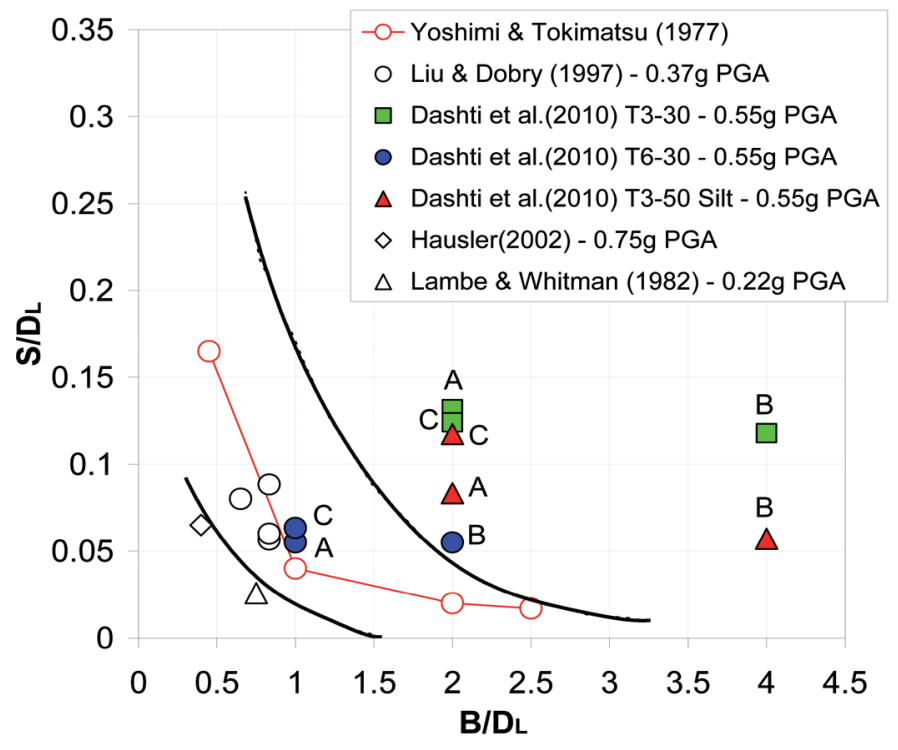

Figure 11: Normalized settlement $\mathrm{S}$ measured in previous centrifuge tests compared with the available case history data of liquefaction induced building settlement

Therefore the widespread normalization by the liquefiable layer thickness $D_{L}$ should be limited to cases where deep potentially liquefiable deposits are present, since it is clearly misleading for thin deposits of saturated sands.

In Dashti et al. (2010) tests structural model B settled more than structural model A, having a higher contact area (see Figure 9). As expected, both models settled less when placed on the denser sand capped profile. Structural model $\mathrm{C}$, representing a taller building having a contact pressure of approximately $130 \mathrm{kPa}$, presented a more complex behaviour; despite settling slightly less with respect to building A (exerting a contact pressure of $80 \mathrm{kPa}$ ), when placed on the loose sand model. In the dense test it settled significantly more than the other buildings. This behaviour may be ascribed to an amplification of the SSI induced shear stresses due to its higher contact pressure and higher centre of gravity. This observation points out that for tall (hence heavy) buildings the deviatoric component of the deformation may in some cases prevail over the volumetric component, and must therefore be accounted for carefully when analyzing the settlement of such structures.

\section{Conclusions}

A review of the field and experimental case history of 
the liquefaction induced settlement of buildings with shallow foundations has been presented. In particular, foundation induced confinement has been shown to be an important factor that was not previously formally taken in consideration in the current methodology used for the estimation of this type of settlement. Field observations suggest that heavier (i.e. taller) buildings or those surrounded by other structures suffered smaller settlements (Liu and Dobry, 1997), this is in line with the pore pressure ratios measured in centrifuge and shaking table tests, which showed to be lower underneath the foundation with respect to the free-field. Moreover, excess pore pressure ratios showed to be inversely proportional to the foundation's bearing pressure (Yoshimi \& Tokimatsu, 1977).

In the presence of a capping low permeability layer the excess pore pressure ratios generated as a consequence of ground shaking were maintained for a longer period of time because of their slower dissipation through the finer material top layer. Excess pore water pressure in the freefield was maintained far longer than the time needed for the complete sedimentation of the liquefied soil, suggesting the generation of a water film at the sand-silt interface in the free-field, while underneath the foundation model the excess pore pressures generated were not big enough to equal the increased overburden pressure (Liu and Dobry, 1992).

A series of centrifuge tests is currently being carried out at University of Dundee, in order to further investigate the effect of shallow foundation vertical confining stress and soil stratification pattern on the liquefaction induced settlement of such structures.

\section{Acknoledgements}

The author is grateful for the financial support to the EPSRC research grant Liquefaction Settlements in Stratified Soils (EP/G016127/1) and to The Royal Academy of Engineering travel grant (ITG 10-822).

\section{References}

Acacio, A., Kobayashi, Y., Towhata, I., Bautista, R. T. and Ishihara, K. (2001). Subsidence of building foundation resting upon liquefied subsoil: case studies and assessment. Soils and Foundation 41(6), 111-128.
Adachi, T., Iwai, S., Yasui, M. and Sato, Y. (1992). Settlement and inclination of reinforced-concrete buildings in DagupanCity due to liquefaction during the 1990 Philippine Earthquake. Proceedings of the $10^{\text {th }}$ World Conference on Earthquake Engineering, Vol. 1, 147-152.

Dashti, S., Bray J. D., Pestana, J. M., Riemer, M. and Wilson, D. (2010). Mechanism of seismically induced settlement of buildings with shallow foundation on liquefiable soil. Journal of Geotechnical and Geoenvironmental Engineering ASCE 136(1), 151-164

EERI (1995). The Hyogo-ken Nanbu (Kobe) earthquake, January 17, 1995: Preliminary Reconnaissance Report, 116p

Fiegel, G.L. and Kutter, B.L. (1994). Mechanism of liquefaction for layered soils. Journal of Geotechnical and Geoenvironmental Engineering ASCE 120(4), 737-755

Ghalandarzadeh, A. and Khaki Khatibi, A.R. (2003). Study on the behaviour of shallow foundations during liquefaction and mitigation methods by means of $1 \mathrm{~g}$ shaking table tests. Proceedings BGA International Conference on Foundations, Dundee, 331-340

Hausler, E. A., (2002). Influence of ground improvement on settlement and liquefaction: a study based on field case history evidence and dynamic geotechnical centrifuge tests. Ph.D. thesis, University of California Berkeley.

Ishihara, K. and Yoshimine, M. (1992). Evaluation of settlements in sand deposits following liquefaction during earthquakes. Soils and Foundations 32(1), 173-188

Liu, L. and Dobry, R. (1992). Centrifuge study of shallow foundation on saturated sand during earthquakes. Proceedings of the $4^{\text {th }}$ U.S.A. -Japan Workshop on Earthquake Resistant Design of Lifeline Facilities and Countermeasures for Soil Liquefaction, Honolulu, 493-508.

Liu, L. and Dobry, R. (1997). Seismic response of shallow foundation on liquefiable sand. Journal of Geotechnical and Geoenvironmental Engineering ASCE 123(6), 557-567

Seed, B. and Lee, K.L. (1966). Liquefaction of saturated sands during cyclic loading. Journal of Soil Mechanics and Foundation Division 92, SM6, 105-134

Seed, H.B. and Idriss, I.M. (1971). Simplified procedures for 
evaluating soil liquefaction potencial. Journal of Soil Mechanics and Foundation Division 97, SM9, 1249-1273

Tokimatsu, K. and Seed, B. (1987). Evaluation of settlements in sand due to earthquake shaking. Journal of Geotechnical Engineering Division ASCE 113, No.8, 861-878

Tokimatsu, K., Kuwayama, S., Abe, A., and Midorikawa, S. (1994). Liquefaction-induced damage to buildings in 1990 Luzon earthquake. Journal of Geotechnical and Geoenvironmental Engineering ASCE 120(2), 290-303

USGS (2006). Photographic library. www.libraryphoto.cr.usgs. gov

Whitman, R.V. and Lambe, P.C. (1982). Liquefaction: consequences for a structure. Proceedings of the Conference on Soil Dynamics and Earthquake Engineering. Rotterdam, 941949

Yoshimi, Y. and Tokimatsu, K. (1977). Settlement of buildings on saturated sands during earthquakes. Soils and Foundations 17(1), 23-28 